\title{
Assessment of Expectation, Attitude and Preconceptions in a Group Patient Applying for Dental Implant Treatment
}

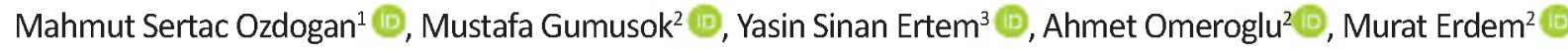 \\ ${ }^{1}$ Department of Prosthodontics, Faculty of Dentistry, Ankara Yildirim Beyazit University \\ ${ }^{2}$ Ministry of Health 75th Year Oral and Dental Health Hospital \\ ${ }^{3}$ Department of Oral and Maxillofacial Surgery, Faculty of Dentistry, Ankara Yildirim Beyazit University \\ Correspondence Author: Mahmut Sertac Ozdogan \\ E-mail: msertacozdogan@gmail.com \\ Received: 24.05.2018 Accepted: 04.09.2018
}

\begin{abstract}
Objective: The aim of this study was to evaluate expectation, attitude, and preconceptions regarding dental implant therapy among a selected sample group of dental patients who applied for implant treatment.

Methods: This cross-sectional hospital-based study was carried out using a questionnaire with 132 patients who applied for implant treatment. The study questionnaire contained 20 multiple-choice questions on the patients' demographics, sources of information, knowledge, attitude, expectations, and related factors regarding dental implant treatment.

Results: Majority of the patients stated that they did not have enough knowledge about implant treatment procedure to be applied. Of the patients, $23.5 \%$ thought that the implant would be used for a lifetime, $56.8 \%$ thought that post-implant care should be like the natural teeth care, $36.4 \%$ stated that implants need more care than natural teeth. They stated that the major disadvantages of implant treatment were the high cost (53.0\%), difficulty in treatment (28.0\%), and long treatment time (18.9\%). It was determined that the main reason for the delay was the high cost of the treatment. As education level rose, the preference for a removable denture decreased $(p<0.05)$

Conclusion: According to the results we obtained from a limited sample, patients may have misinformation and incomplete expectation about implant therapy. Informing and educating the patients is very important for deciding which treatment to pursue and setting realistic patient expectations regarding treatment outcomes.
\end{abstract}

Keywords: Implant therapy, patient, questionnaire

\section{INTRODUCTION}

The artificial replacement of missing teeth with dental implants has become an increasingly common and widely accepted treatment option (1). Periodontal disease, poor oral hygiene, and trauma can cause tooth loss, and dental implants can be a good option for people who do not have general health problems (2). Dental implants can be used to stabilize oral prostheses through fixed bridges and overdentures, which do not have the limitations of removable dentures (3). Dental implants are functionally effective and stronger and more durable than bridges and dentures, so completely or partially toothless patients may prefer dental implants as a prosthetic treatment $(4,5)$. The use of dental implants has an important effect on the prosthodontic treatment of the edentulous patient (6).

Despite the advantages and common clinical use of dental implants, patients' knowledge of dental implants is usually limited and inaccurate. A study in the United States reported that $77 \%$ of patients knew about dental implants, but their main source of information was the media, and they had not received sufficient information from their dentists (7). There is a lack of education and awareness about dental implants as a dental treatment modality among people (8).
Dentists must give patients information about implant treatment and alternative therapies to guide them in the best choice of teeth replacement treatment (9). In addition to increasing patients' knowledge, disseminating social awareness and information about oral implant therapy through media and other communication channels will improve patients' attitudes and implant delivery planning in clinical practice. It is important to determine patients' current level of knowledge, attitudes, and expectations toward dental implant therapy before developing measures to increase the knowledge of patients and society. There are reasonably study, on the knowledge and attitudes regarding dental implant in public; however, studies conducted in patients applying for implant therapy are limited. Accordingly, the aim of this study was to evaluate the knowledge, attitude, preconception, and expectations for dental implant therapy among a selected sample group of dental patients who apply for implant treatment in Ankara, Turkey.

\section{METHODS}

\subsection{Study Design and Population}

This cross-sectional hospital-based study was carried out using a self-administered study questionnaire with 132 
patients ( 77 female and 55 male, mean age: 34 years) who applied to the 75 Year Oral and Tooth Health Hospital, for implant treatment between 18 May - 29 September 2017. The study was approved by the Ethics Committee of Faculty of Dentistry at Ankara University (May 17, 2017, No. 09/04) and conducted in accordance with the most recent guidelines of the Declaration of Helsinki. The patients or their legal representatives were informed about this study before any study-related procedure and written consent was obtained from patients.

\subsection{Study Questionnaire}

The researchers designed the questionnaire based on previous studies using similar questionnaires $(7,10)$. It contained 20 multiple-choice questions on the patients' demographics and education, sources of information on implants, knowledge about implants, and awareness, attitudes, and expectations for dental implant treatment.

\subsection{Statistical Analysis}

The data were summarized using descriptive statistics (i.e., frequency and percentage). The chi-square test was used to evaluate the effects of educational level, age, and gender on knowledge and attitudes toward implant treatment. All statistical analyses were performed using Statistical Package for the Social Science Programme (SPSS version 20.0 for Windows, Inc, Chicago, IL). The level of statistical significance was set at $p<0.05$.

\section{RESULTS}

\subsection{Sociodemographics of the Study Population}

Of the 132 patients who completed the study questionnaire, $77(58.3 \%)$ were female, $96(72.7 \%)$ were $18-40$ years old, and $101(83.5 \%)$ had graduated from high school or university (Table 1).

Table 1. Sociodemographic characteristics of patients.

\begin{tabular}{|c|l|c|}
\hline \multicolumn{1}{|c|}{ Variables } & \multicolumn{1}{|c|}{$\mathbf{n}(\%)$} \\
\hline \multirow{2}{*}{ Gender } & Male & $55(41.7 \%)$ \\
\cline { 2 - 3 } & Female & $77(58.3 \%)$ \\
\hline \multirow{2}{*}{ Education } & $18-40$ & $96(72.7 \%)$ \\
\cline { 2 - 3 } & 41 and above & $36(27.3 \%)$ \\
\cline { 2 - 3 } & Primary and secondary school & $31(23.5 \%)$ \\
\cline { 2 - 3 } & High school & $47(35.6 \%)$ \\
\cline { 2 - 3 } & University & $54(40.9 \%)$ \\
\hline \multirow{2}{*}{ Total } & \multicolumn{2}{|c|}{$132(100.0 \%)$} \\
\hline
\end{tabular}

\subsection{Patients' Knowledge, Attitudes, and Expectations for Dental Implants}

In the questionnaire results, more than half of the patients (54.5\%) stated that they had sufficient information about missing teeth treatments. Half received information on dental prosthesis from their dentists, and $87 \%$ did not prefer removable prosthesis. As well, 50.8\% had knowledge about dental implants, and of these patients, only $31.8 \%$ obtained this information from dentists. The rest obtained information from other sources. High cost $(41.7 \%)$ was the leading reason for delaying implant treatment. In addition, $56.8 \%$ of the patients thought that implants could be cleaned like natural teeth, $66.7 \%$ believed that implants were attached to the jawbone, and $53 \%$ reported that high cost was the main disadvantage of implants (Table 2).

While $37.9 \%$ of the patients had no idea about the lifetime of dental implants, $23.5 \%$ thought that they could be used for life. Regarding the causes of implant loss, $25 \%$ cited misuse by patients and $12.9 \%$ misuse by dentists. As well, $67.4 \%$ of the patients did not know about the implant surgery procedure, and $80.3 \%$ considered the costs of dental implant procedure to be expensive. Almost all of the patients (95.5\%) stated that the Social Security Institution, the governing authority of the Turkish social and health security system, should pay for implant treatment. Finally, $84.8 \%$ of the patients thought that a brochure or booklet about dental implant care would be useful (Table 2).

\subsection{Effects of Demographics and Education Level on Patients' Attitudes towards Dental Implants}

There was no difference between male and female patients' attitudes toward dental implants, except toward insurance coverage of dental implants. Significantly more female patients $(98.2 \%)$ than male patients $(93.5 \%)$ stated that the Social Security Institution should cover the cost of implant treatment $(p=0.040)$ (Table 3$)$. Older patients ( $\geq 41$ years old) had more informed on the implant surgery procedure than younger patients (18-40 years old) $(74.0 \%$ and $50.0 \%$, respectively; $p=0.048$ ) (Table 3 ). Not preferring a removable prosthesis and not considering informative brochures on dental implant to be useful were significantly higher among younger patients than older patients $(P<0.05)$ (Table 3 ). There was a statistically significant relationship between the level of education of the patients and thinking about having sufficient information about the treatment options for missing teeth ( $p=0.047)$ (Table 3). The patients' education level had a significant effect on the preference for a removable prosthesis and view of informative brochures on dental implants as useful. As education level rose, the preference for a removable prosthesis decreased $(p=0.025)$, and views of informative brochures on dental implants as useful increased $(p=0.038)$ (Table 3$)$.

\section{DISCUSSION}

The high success rates of dental implant treatment drive patients to see them as the first choice for replacement of missing teeth. Increasing knowledge of this advanced treatment modality logically leads to greater social acceptance (11). Studies on dental implants have mostly 
Table 2. Patients' Responses to the Questionnaire Items on Dental Implants ( $n=132)$

\begin{tabular}{|c|c|c|}
\hline Questions & Answers & $n(\%)$ \\
\hline \multirow{2}{*}{$\begin{array}{l}\text { Do you think you have information on the treatment } \\
\text { options for missing teeth? }\end{array}$} & Yes & $72(54.5)$ \\
\hline & No & $60(45.5)$ \\
\hline \multirow{5}{*}{$\begin{array}{l}\text { If yes, where did you learn about the types of dental } \\
\text { prosthesis you can use? }\end{array}$} & Dentist & $66(50.0)$ \\
\hline & Friends and relatives & $13(9.8)$ \\
\hline & Television and radio & $6(4.5)$ \\
\hline & Newspapers and magazines & $0(0.0)$ \\
\hline & Websites & $6(4.5)$ \\
\hline \multirow[t]{2}{*}{ Do you prefer a removable prosthesis? } & Yes & $17(12.9)$ \\
\hline & No & $115(87.1)$ \\
\hline \multirow[t]{2}{*}{ Did you hear about dental implant therapy before? } & Yes & $67(50.8)$ \\
\hline & No & $65(49.2)$ \\
\hline \multirow[t]{5}{*}{ If yes, where did you hear dental implant therapy before? } & Newspapers & $1(0.8)$ \\
\hline & Television and radio & $21(15.9)$ \\
\hline & Dentist & $42(31.8)$ \\
\hline & Friend & $10(7.6)$ \\
\hline & Person with an implant & $10(7.6)$ \\
\hline \multirow{3}{*}{$\begin{array}{l}\text { If you have heard of dental implant therapy before, why you } \\
\text { did not consider this treatment until now? }\end{array}$} & High cost & $55(41.7)$ \\
\hline & Unclear treatment procedure & $7(5.3)$ \\
\hline & I was not informed by the dentist. & $4(3.0)$ \\
\hline \multirow{4}{*}{$\begin{array}{l}\text { Do you think that dental implants require special care and } \\
\text { hygiene? }\end{array}$} & They can be cleaned like natural teeth. & $75(56.8)$ \\
\hline & They need more care than natural teeth. & $48(36.4)$ \\
\hline & They need less care than natural teeth. & $7(5.3)$ \\
\hline & They require no maintenance. & $2(1.5)$ \\
\hline \multirow[t]{4}{*}{ Where do you think dental implants are placed in mouth? } & Gingiva & $9(6.8)$ \\
\hline & Neighboring teeth & $6(4.5)$ \\
\hline & Jawbone & $88(66.7)$ \\
\hline & No idea & $29(22.0)$ \\
\hline \multirow{3}{*}{$\begin{array}{l}\text { What are the disadvantages of implant-supported } \\
\text { prostheses/bridges? }\end{array}$} & The price is high. & $70(53.0)$ \\
\hline & The process of treatment is long, & $25(18.9)$ \\
\hline & The treatment is difficult. & $37(28.0)$ \\
\hline \multirow[t]{5}{*}{ How long do you think implants last? } & Up to 5 years & $7(5.3)$ \\
\hline & Up to 10 years & $26(19.7)$ \\
\hline & Up to 20 years & $18(13.6)$ \\
\hline & Lifelong & $31(23.5)$ \\
\hline & No idea & $50(37.9)$ \\
\hline \multirow{5}{*}{$\begin{array}{l}\text { Some patients lose their implants. What are the causes of } \\
\text { implant loss? }\end{array}$} & Patient & $33(25.0)$ \\
\hline & Dentist & $17(12.9)$ \\
\hline & Allergies and incompatibilities & $31(23.5)$ \\
\hline & Poor hygiene and cleaning & $24(18.2)$ \\
\hline & No idea & $54(40.9)$ \\
\hline \multirow{2}{*}{$\begin{array}{l}\text { Do you have information on the procedure of implant } \\
\text { surgery? }\end{array}$} & Yes & $43(32.6)$ \\
\hline & No & $89(67.4)$ \\
\hline \multirow[t]{2}{*}{ How do you assess treatment costs of dental implants? } & Economic & $26(19.7)$ \\
\hline & Expensive & $106(80.3)$ \\
\hline \multirow{2}{*}{$\begin{array}{l}\text { Do you think the Social Security Institution in our country } \\
\text { should cover implant treatment? }\end{array}$} & Yes & $126(95.5)$ \\
\hline & No & $6(4.5)$ \\
\hline \multirow{2}{*}{$\begin{array}{l}\text { Do you think a brochure or booklet about dental implant } \\
\text { care would be useful? }\end{array}$} & Yes & $112(84.8)$ \\
\hline & No & $20(15.2)$ \\
\hline
\end{tabular}


Table 3. Effect of gender, age, and education of patients on their attitudes towards dental implants ( $n=132$ )

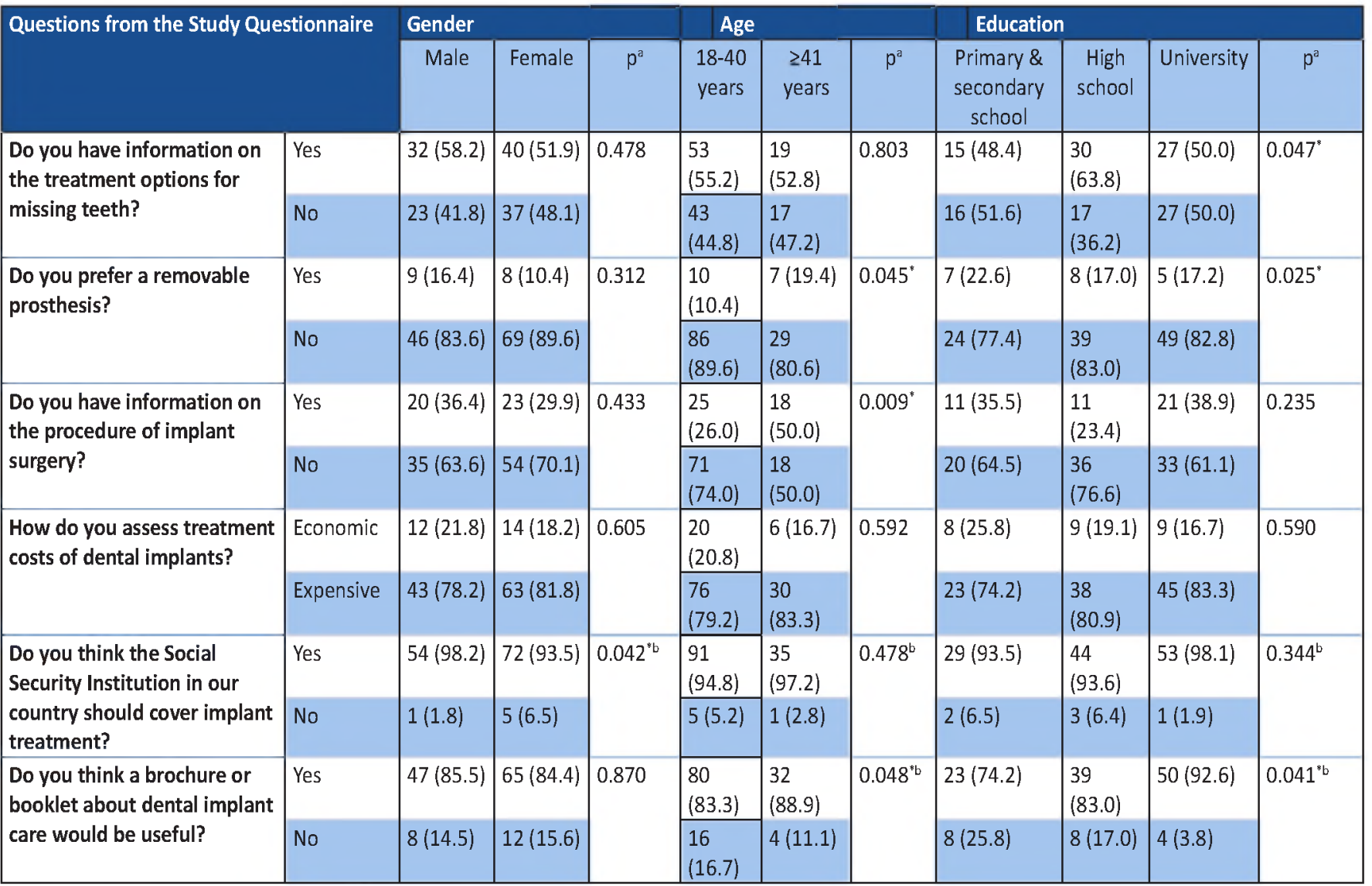

${ }^{\sigma}$ Chi-square test. ${ }^{b}$ Exact chi-square test ${ }^{*}$ Statistically significant difference at the level of $p<0.05$.

focused on the efficacy and safety of the procedure rather than patients' knowledge and attitudes toward them. To assess the current situation before planning measures to increase awareness of dental implants among patients and society, the present survey was conducted to determine the knowledge level, expectations, and attitudes regarding dental implants among a selected group of dental patients in Turkey. Although the study population consisted of patients who had applied for implant therapy, only half had knowledge about dental implants across age, gender, and education.

In recent years, patient access to dental treatment has increased. Hospital-based surveys on patients' awareness, knowledge, acceptance, and views on this special treatment option provide data that can be used to reveal patient education and motivation strategies, local treatment policies, and guidelines for dental implants (11).

Previous studies have reported a relation between sociodemographic factors and tendency towards implant treatment $(12,13)$. Berge et al. (12) reported that highly educated young men with high incomes living in urban areas had a positive tendency, while older women with less education and income living in rural areas displayed more skepticism toward oral implant treatment. Zimmer et al. (13) found that younger adults had significantly stronger preferences for implants than older adults. In our study, however, the patients' age, gender, and education had no or limited effects on their attitudes toward dental implants. Older and more educated patients expressed a higher preference for written information on dental implants (e.g., brochures and booklet). Older patients had more information on the implant surgery procedure.

The present study showed that dentists were the main source of information about missing teeth treatment with dental implants, similar to another study from Turkey (14). This finding accorded with those of Ravi Kumar et al. (11) but conflicted with those of Berge and Zimmer et al. (13), who reported that the media was the main information source for dental implants. In an Austrian study, $68 \%$ of 1,000 participants had received information from their dentists (7). These disparate findings may be explained by differences in culture and healthcare systems. In Turkey, factors such as compulsory health insurance and widespread private and public dental care services make it easier for patients to access dentists. In the present study, most patients thought they did not have enough information about the implant surgery procedure. We think that it is more important for patients to be informed about the potential risks and failures of dental implants than technical details, such as the material and osseointegration time.

Several factors, such as the type of prosthesis and the number of implants placed, affect the cost of implant prostheses. In our study, high cost was the most frequent reason for the patients to delay or not consider implant treatment, and the majority of the patients thought that dental implants were expensive. Japanese patients named cost and surgery 
as primary reasons for negative attitudes toward implant therapy (15), while Canadian patients cited concerns about surgical risks as the major reason for refusal of implant treatment (16). We, therefore, suggest that it is important to explain and clarify to patients the connection between costs and potential treatment outcomes.

The high cost indicates a need for dental insurance coverage of dental implants to increase acceptance of the treatment among the Turkish people. Implant treatment is a costly procedure, and the majority of the patients felt that they needed insurance coverage to undergo it. Similarly, Chowdhary et al. (17) and Kumar et al. (18) reported that $96 \%$ and $91.3 \%$ of the study population, respectively, thought that insurance coverage was necessary to undergo implant treatment.

Most of the patients had no knowledge or false knowledge how long dental implants lasted. Similarly, Tomruk et al. (14) reported that only $16 \%$ of study population believed that their implants would last forever. Ajayi et al. (9) reported that $68.7 \%$ of the population had no idea of how long dental implants would be used, while in an earlier study, $60 \%$ of patients expected dental implants to last around 5 years, and $12.7 \%$ for a whole lifetime (19). However, $28 \%$ of the patients in another Japanese study expected that implants would last for life (15).

The majority of our patients thought that cleaning implants like natural teeth would be sufficient, and only $25 \%$ thought that implant loss was due to patients' misuse of prosthesis. However, plaque develops more rapidly and in larger amounts around abutments of titanium implant compared to natural teeth (20). Maintenance costs are much higher for implants than natural teeth (21). Patients should be clearly informed that dental implants are expected to last a lifetime if patients maintain dental hygiene and have regular dental checkups.

After dental implant treatment, giving patients material on guidelines for dental implant care (e.g., a brochure or booklet) is helpful. In this study, most of the patients $(84.8 \%)$, especially older and highly educated patients, were interested in such guidelines.

The limitation of this study is that it was applied only in one dental center and had a relatively small sample, which precluded extrapolating the results for broader Turkish society and dental patients. Nevertheless, this study is one of few studies in Turkey on patients' attitudes toward dental implants and can form the basis for further large-scale studies.

\section{CONCLUSION}

In conclusion, Turkish patients applying for implant therapy have incomplete and inaccurate information about dental implants. Informing and educating patients about implant therapy will result in better treatment decisions, more realistic posttreatment expectations, and longer use of the prosthesis. Dentists who take care of these responsibilities will reduce the number of potential problems. Patient education by dentists is especially important to achieve the goal to increase awareness and prevent misinformation about dental implants in society.

\section{REFERENCES}

[1] Sahoo S, Suvarna SR, Sethi K, Kumar P. Awareness and need of dental implant therapy as pertinent to indian situation: an overview. Int J Med Public Health 2013;3:124-125.

[2] Oshida Y, Tuna EB, Aktören O, Gençay K. Dental implant systems. Int J Mol Sci 2010;11: 1580-1678.

[3] Allen PF, McMillan AS. A longitudinal study of quality of life outcomes in older adults requesting implant prostheses and complete removable dentures. Clin Oral Implants Res 2003;14:173-179.

[4] Mgbeokwere U, Okoye L, Ekwueme OA. Survey of the knowledge of dental implants as a choice in treatment of edentulous jaws among health workers in Government Dental Clinics in Enugu. Ann Med Health Sci Res 2011;1: 91-96.

[5] Naert I, Koutsikakis G, Duyck J, Quirynen M, Jacobs R, van Steenberghe D. Biologic outcome of implant-supported restorations in the treatment of partial edentulism. Part I: a longitudinal clinical evaluation. Clin Oral Implants Res 2002;13: 381-389.

[6] Mericske-Stern RD, Taylor TD, Belser U. Management of the edentulous patient. Clin Oral Implants Res 2000;11(1): 108125.

[7] Tepper G, Haas R, Mailath G, Teller C, Bernhart T, Monov G, Watzek G. Representative marketing-oriented study on implants in the Austrian population. II. Implant acceptance, patient-perceived cost and patient satisfaction. Clin Oral Implants Res 2003; 14(5):634-642.

[8] Saha A, Dutta S, Vijaya V, Rajnikant N. Awareness among patients regarding implants as a treatment option for replacement of missing teeth in Chattisgarh. J Int Oral Health 2013;5: 48-52.

[9] Ajayi YO, Akinboboye BO, Dosumu OO, Akeredolu PA. Awareness of dental implants among dental patients in Nigeria. JMBR 2016;15: 40-48.

[10] Kohli S, Bhatia S, Kaur A, Rathakrishnan T. Trends in patients' mindset on dental implants: a survey in Malaysia. J Dent Implant 2014;4: 33-37.

[11] Ravi Kumar C, Pratap KVNR, Venkateswararao G. Dental implants as an option in replacing missing teeth: a patient awareness survey in Khammam, Andhra Pradesh. Ind J Dental Sci 2011;3: 33-37.

[12] Berge TI. Public awareness, information sources and evaluation of oral implant treatment in Norway. Clin Oral Implants Res 2000; 11:401-408.

[13] Zimmer CM, Zimmer WM, Williams J, Liesener J. Public awareness and acceptance of dental implants. Int J Oral Maxillofac Implants 1992;7: 207-217.

[14] Ozçakır TC, Ozkurt-Kayahan Z, Sençift K. Patients' knowledge and awareness of dental implants in a Turkish subpopulation. J Adv Prosthodont 2014;6: 133-137.

[15] Akagawa Y, Rachi Y, Matsumoto T, Tsuru H. Attitudes of removable denture patients toward dental implants. J Prosthet Dent 1988;60: 362-364. 
[16] Rustemeyer J, Bremerich A. Patients' knowledge and expectations regarding dental implants: assessment by questionnaire. Int J Oral Maxillofac Surg 2007;36:814-817.

[17] Chowdhary R, Mankani N, Chandraker NK. Awareness of dental implants as a treatment choice in urban Indian populations. Int J Oral Maxillofac Implants 2010;25: 305-308.

[18] Kumar S, Chauhan A. Knowledge and awareness of denta implants in India: an exploratory study. Int J Oral Health Med Res 2015;2: 29-33.

[19] Satpathy A, Porwal A, Bhattacharya A, Sahu P. Patient awareness, acceptance and perceived cost of dental implants as a treatment modality for replacement of missing teeth: $A$ survey in Bhubaneswar and Cuttack. Int J Pub Health Dentistry 2011;2: 1-7.

[20] Patil SH, Veena HR, Chakrasali MS, Shah AC. Dental Implant Maintenance-A Review. International Journal of Dental Clinics 2011;4: 35-40.

[21] Fardal Q, Grytten J. A comparison of teeth and implants during maintenance therapy in terms of the number of diseasefree years and costs-an in vivo internal control study. J Clin Periodontol 2013;40:645-665. 